\title{
Pervaporation Separation of Water-Ethanol Through Modified Polyacrylonitrile Membranes ${ }^{\dagger}$
}

\author{
Young Moo LEE* and Kook WoN \\ Department of Industrial Chemistry, College of Engineering, \\ Hanyang University, Seoul 133-791, Korea
}

(Received January 19, 1990)

\begin{abstract}
In the present work the separation of water-ethanol binary mixture through polyacrylonitrile (PAN) and its modified membranes was studied using pervaparation processes. PAN was chosen as a base polymer because of its high affinity with water. As a result, homogeneous PAN membrane has an extremely high selectivity toward water and has low fluxes in pervaparation. Membrane morphology of PAN influences to a great extent on the membrane performance when separating the aqueous ethanol solution. This study investigates the way to control the membrane morphology and the membrane performance. The key factors affecting the membrane morphology include the membrane casting variables such as concentration of casting solution, solvent evaporation temperature, solvent evaporation pressure, the membrane thickness and the presence of nonsolvents in casting solution. Membranes we investigated are homogeneous, blend-type and copolymer-type PAN membranes. A statistical method was adopted in the experiment. As a consequence it was possible to effectively predict fluxes and separation factors using these membranes to dehydrate aqueous ethanol solution.
\end{abstract}

KEY WORDS Pervaporation / Polyacrylonitrile Membrane / Blend Membrane / Copolymer Membrane / Separation Factor / Water-Ethanol Mixture /

Pervaporation is a membrane separation process that can be applied to separate organic-water mixtures. Particularly for ethanol-water solution, we looked for ethanol selective membranes. ${ }^{1}$ In this case, however, a great deal of research efforts has been focused on the separation near the azeotropic composition. For this application, a lot of work has been done to develop more efficient membranes. ${ }^{2-6}$ Good selectivities for water has been obtained using hydrophilic groups or by the inclusion of this group in the membrane structure. $^{7-9}$

Increasing hydrophilicity, however, normally induces an increase of the solubility of the polymer in water, and as a consequence the membrane may dissolve in water solution. It is possible to decrease the polymer solubility by blending, copolymerization or crosslinking, induced by chemical reactions. As a result of these treatment an increase in selectivity and a decrease in membrane flux are observed. Chemically modified polyacrylonitrile membranes have been extensively studied by Yoshikawa et al. ${ }^{7-9}$ They obtained maximum separation factor of up to 2000 for water in poly[1-(2-methylpropenoxyloxy)-succinimideco-acrylonitrile] membrane. Most of their membranes have in general low separation factor with low fluxes (not exceeding $100 \mathrm{~g}$ $\mathrm{m}^{-2} \mathrm{~h}^{-1}$ with $\alpha$ of 100 ). They observed a typical inverse relationship between separation factor

${ }^{\dagger}$ This paper has been presented at the Fourth International Conference on Pervaporation Processes in the Chemical Industry, held in Ft. Lauderdale, Florida, on December 3-7, 1989.

* To whom all correspondence should be addressed. 
and flux.

Commercial GFT membrane incorporates poly(vinyl alcohol) dense layer on top of polyacrylonitrile porous sublayer. It is known that for dehydration of ethanol separation factor ranges from 50 to 400 with flux values of 0.05 to $1.0 \mathrm{~kg} \mathrm{~m}^{-2} \mathrm{~h}^{-1}$ when feed water concentration is about $10 \mathrm{wt} \%$ and feed temperature is about $60-100^{\circ} \mathrm{C}^{3}$ Meanwhile Smolders et al. ${ }^{10}$ reported that homogeneous PAN membranes perform separation factor of up to 2000 with flux values of only $8.5 \mathrm{~g} \mathrm{~m}^{-2} \mathrm{~h}^{-1}$. They also observed typical inverse relationship between membrane thickness and flux.

The objective of this study is to manufacture in a laboratory scale polyacrylonitrile membranes with high flux and separation factor for ethanol-water separation. In the present work homogeneous polyacrylonitrile, PAN blended with cellulose acetate and copolymer with acrylic acid were prepared, and membranes therefrom are used in dehydration of ethanolwater mixtures. For blended membranes a statistical method was used to control the membrane thickness and casting conditions.

\section{EXPERIMENTAL}

\section{Materials}

Polyacrylonitrile (PAN) was obtained from Hanil Synthetic Fibers Co. (Seoul, Korea). It contains about $9 \mathrm{wt} \%$ methylmethacrylate with moleculer weight of about $80000(\rho=1.175$ $\mathrm{g} \mathrm{cm}^{-3}$ and $[\eta]=0.14-0.19$ ). Acrylonitrile (AN) monomer and acrylic acid (AA) monomer was from Junsei Chemical Co., Ltd. Dimethyl formamide (DMF) used were from Jin Chemical. Cellulose acetate (CA) was obtained from Eastman Kodak [E-398-3] and was used after recrystallization with acetone. Iso-butyric acid was from Junsei Chemical Co., Ltd. Acetic acid and acetone were from Jin Chemical.

\section{Membrane Preparation}

Preparation of Homogeneous Polyacrylonitrile $(P A N)$. A $10 \mathrm{wt} \%$ solution of commercial PAN in DMF was prepared to form a homogeneous solution. The casting solution was cast onto a glass plate with the aid of a Gardner casting knife to appropriate thickness, pre-dried at room temperature and then dried at $60^{\circ} \mathrm{C}$ for $2 \mathrm{~h}$ in a vacuum oven. Membrane was peeled off from the glass plate and then redried in a vacuum oven for 2 days.

Preparation of PAN Membranes from Casting Solution Containing Nonsolvent. A $10 \mathrm{wt} \%$ solution of PAN in DMF and nonsolvent was prepared. Iso-butyric acid, acetic acid, acetone and water were nonsolvents used. The casting solution was cast onto a glass plate and then dried at $65^{\circ} \mathrm{C}$ for $4 \mathrm{~h}$.

Preparation of Blended PAN-CA Membranes. A $10 \mathrm{wt} \%$ solution of commercial PAN and CA in DMF was prepared with a different blend ratio. A Box-Behnken design has been built by using four factors taken at three levels. The four variables are PAN-CA blend ratio, solvent evaporation temperature, solvent evaporation pressure and membrane thickness. For each response the mean effect and first order interactions were determened by using Statistical Analysis System (SAS) computer program. ${ }^{11}$

Preparation of AN-AA Copolymer Membranes. AN and AA in $60 \mathrm{wt} \%$ aqueous zinc choride and with varying molar ratios were placed in a four necked flask filled with ammonium persulfate as an initiator. The copolymerization was carried out at $60^{\circ} \mathrm{C}$ with a continuous stirring. The mixture was poured into water, filtered and dried in a $60^{\circ} \mathrm{C}$ oven for $24 \mathrm{~h}$. Copolymer membranes were prepared with a $10 \mathrm{wt} \%$ solution in DMF.

Pervaporation Experiment. The pervaporation apparatus consisted of a permeation cell made of stainless steel, a constant temperature bath, and glass tubes for condensing and collecting the permeate vapor. The upstream compartment had a capacity of $500 \mathrm{~cm}^{2}$, and 
the membrane area in contact with liquid was about $25.98 \mathrm{~cm}^{2}$. The downstream pressure was maintained from 400 to $670 \mathrm{~Pa}$ (3-5 Torr). Pervaporation experiments were carried out at constant temperature of $20,50,70,90^{\circ} \mathrm{C}$, respectively. A detailed description of the apparatus is appeared elsewhere. ${ }^{1}$

The separation analysis was carried out on a Shimadzu 6A gas chromatograph equipped with a 3-m long column packed with Porapak $\mathrm{Q}$ and with thermal conductivity detector.

The separation factor, $\alpha_{1 / 2}$, is defined as

$$
\alpha_{1 / 2}=\frac{Y_{1} / Y_{2}}{X_{1} / X_{2}}
$$

where $Y_{i}^{\prime}$ 's are the weight fractions of permeates and $X_{i}$ 's are those of the feeds, and 1 and 2 denote water and ethanol, respectively.

\section{RESULTS AND DISCUSSION}

\section{Homogeneous PAN Membranes}

Our preliminary study shows that the separation factor of PAN membrane is more than 10,000 and flux is about $0.02 \mathrm{~kg} \mathrm{~m}^{-2} \mathrm{~h}^{-1}$. Figure 1 shows the effect of feed temperature on permeation behavior of polyacrylonitrile membrane when $90 \mathrm{wt} \%$ ethanol is used as a feed solution. As expected, water flux increases with feed temperature. The increase of ethanol flux in PAN membrane, however, is much more significant as feed temperation goes up, resulting in a drop in separation factor. There is a significant increase in water and ethanol flux when temperature of feed reaches near a glass transition temperature of PAN $\left(\mathrm{ca} .80^{\circ} \mathrm{C}\right)$. Thermal motion of polymer appears to increase permeation of the solutes.

Figure 2 shows the effect of ethanol feed concentration on total flux, water flux, ethanol flux and separation factor of homogeneous PAN membrane. As feed ethanol concentration ranges from 10 to $90 \mathrm{wt} \%$ ethanol, water flux remains relatively constant while ethanol flux drops sharply, resulting in a maximum separation of water and ethanol in the feed

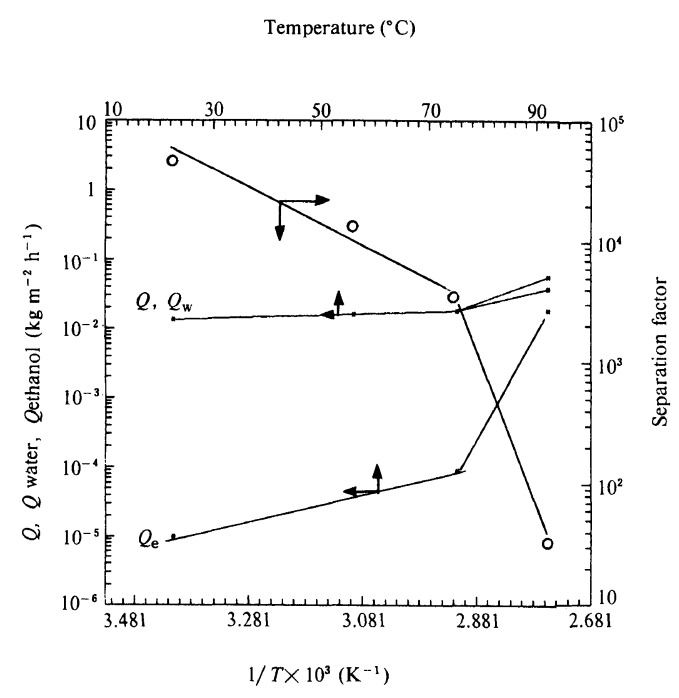

Figure 1. Effect of temperature on permeation flux of solution, water and ethanol in polyacrylonitrile membrane. Feed solution $=90 \mathrm{wt} \%$ ethanol.

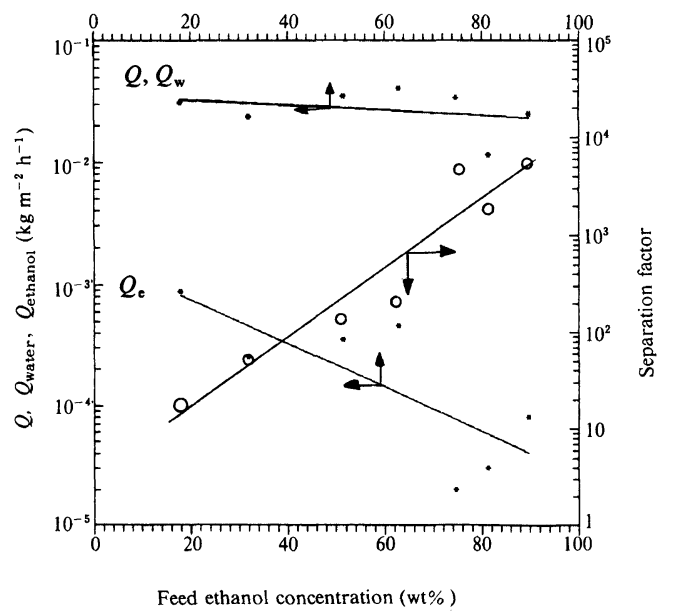

Figure 2. Effect of feed ethanol concentration on the performance of homogeneous polyacrylonitrile membrane. Feed temperature is $25^{\circ} \mathrm{C}$.

ethanol concentration ranging from 70 to $90 \mathrm{wt} \%$. Since polyacrylonitrile is relatively hydrophilic in a sense that solubility parameter of PAN is about $15\left(\mathrm{cal} \mathrm{cm}^{-3}\right)^{1 / 2}$ and that it has a polar nitrile group attached to a repeat unit of main chain, it is understandable that PAN shows a high permselectivity to water rather than ethanol. 
Table I. Effect of nonsolvents in casting solution on pervaporation performance for polyacrylonitrile membranes

\begin{tabular}{|c|c|c|c|c|}
\hline \multirow{2}{*}{ Nonsolvent $^{\mathrm{d}}$ vehicle } & Molar volume & Total flux, $Q$ & \multirow{2}{*}{$C_{\mathrm{p}}\left(\mathrm{H}_{2} \mathrm{O}\right)$} & \multirow{2}{*}{$\alpha$} \\
\hline & $\mathrm{ml} \mathrm{mol}^{-1}$ & $\mathrm{~g} \mathrm{~m}^{-2} \cdot \mathrm{h}^{-1}$ & & \\
\hline $\mathrm{DMF}^{\mathrm{a}}$ & 77.38 & 20 & 99.83 & 5000 \\
\hline DMF : $\mathrm{H}_{2} \mathrm{O}$ & 95.38 & 32 & 97.20 & 259 \\
\hline $\mathrm{DMF}: \mathrm{AcOH}^{\mathrm{b}}$ & 134.62 & 41 & 99.41 & 1412 \\
\hline DMF : Acetone & 151.09 & 29 & 99.42 & 1499 \\
\hline DMF : IBA ${ }^{c}$ & 170.12 & 48 & 98.82 & 530 \\
\hline
\end{tabular}

a $\mathrm{DMF}=N, N$-dimethylformamide.

b $\mathrm{AcOH}=$ acetic acid.

c IBA = iso-butyric acid.

d Amount of nonsolvent, DMF/nonsolvent=10/1 (wt \%); amount of polymer, polymer/solvent =1/9 (wt $\%)$; Membrane thickness ranges, $25-30 \mu \mathrm{m}$; feed ethanol concentration $=87-90 \mathrm{wt} \%$.

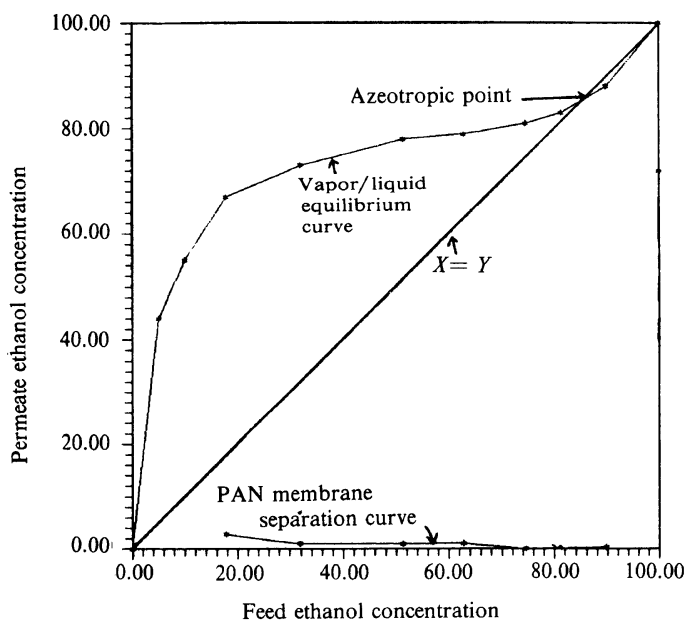

Figure 3. Pervaporation curve of PAN membranes and vapor liquid equilibrium for ethanol/water mixtures.

Figure 3 compares pervaporation performance of PAN membrane and the McCabeThiele curve for ethanol/water mixture. As can be seen in Figure 3, PAN membrane has an excellent separation curve in all concentration ranges of ethanol. It can be, however, used as a pervaporation membrane when we improve the permeability of PAN membrane.

\section{PAN membrane from Casting Solution Contain- ing Nonsolvents}

Kesting reported the effect of solvent size on permeation when solvents and solvent com- plexes were added to the casting solution to prepare asymmetric polysulfone hollow fiber membranes for gas separation. ${ }^{12}$ As the solvent size, that is, the molar volume of the solvent, becomes larger, the resultant asymmetric membranes have an increased free volume and the decreased macromolecular packing density due to large solvents. Therefore the gas flux and separation factor increase simultaneously.

In a similar manner we manufactured the homogeneous PAN membrane from casting solution containing various nonsolvents. They are iso-butyric acid, acetic acid, acetone and water. The results are summarized in Table I. From the results of pervaporation experiment using these membranes we observed a tendency similar to what Kesting reported when nonsolvent was added into the casting solution for ethanol-water separation. In general flux increases with the molar volume of the solvent vehicle except in DMF:acetone. Although acetone is a nonsolvent for PAN, we do not see any solvent size effect or molar volume effect on flux for DMF : acetone case because acetone does not form a complex with DMF. When IBA was added to the casting solution, the flux of PAN membrane showed 2.5 times greater than that of homogeneous PAN membrane without containing nonsolvents in the casting solution. Large solvent molecules and complexes served to increase the cross- 
sectional area of solvated polymer chains which influences the average interchain displacement in the final membrane. A similar effect could be observed for permeant species in the form of bulky side chain groups which serve to increase interchain displacements. ${ }^{13}$ Note that separation factor of above 500 could be regarded as a good indicator of membrane materials for pervaporation in the separation of ethanol-water mixture.

\section{PAN/CA Blend Membranes}

Polyacrylonitrile is known to be a glassy polymer. In general glassy polymers such as PAN, polyimides, polysulfone, polyphenylene oxide show low permeability and high selectivity for gas separation. ${ }^{13}$ For these polymers, plasticization is minimal and mobility selectivity, which is a ratio of diffusion coefficient of one component to another, is governing rather than solubility selectivity. Cellulose acetate is known to exhibit high solubility selectivity. Kapton polyimide membrane shows a similar performance to polyacrylonitrile membrane in separating ethanolwater mixture. ${ }^{14}$

We have looked for polymer materials which can enhance the permeation flux of water with a minimal sacrifice of separation factor. We can pursue this objective in two ways. One way is to physically increase the intersegmental chain displacement and free volume by blending with less glassy polymer having a fairly sufficient solubility to water. Another way to increase the flux might be to increase the solubility selectivity by providing more sites of water sorption such as through incorporating more polar groups in the base polymer. Cellulose acetate meets our need from the literature survey ${ }^{15}$ and was selected as one of the component of blend membrane. Cellulose materials selectively permeates water rather than ethanol and have relatively higher permeation rate than glassy polymers such as PAN and polysulfone.

In Figure 4, the effect of polyacrylonitrile

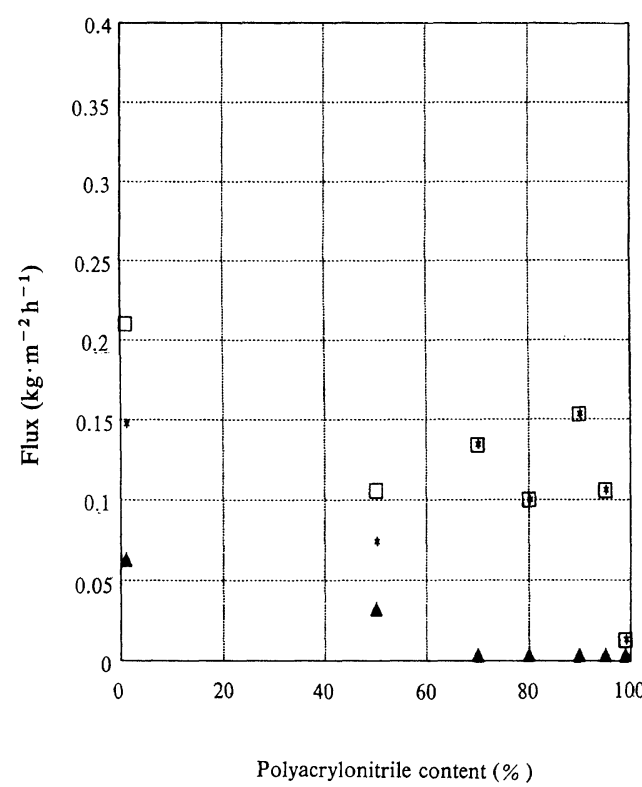

Figure 4. Effect of polyacrylonitrile contents in PAN/CA blend membrane on total solution flux $(\square)$, water flux (*), and ethanol flux (A) when $90 \mathrm{wt} \%$ ethanol solution was used as a feed. Feed temperature $=25^{\circ} \mathrm{C}$.

content (wt\%) in PAN/CA blend membrane on permeation flux of solution, water and ethanol is illustrated. Permeation flux increases with cellulose acetate contents in blend membrane. Note that the flux of CA is about ten times higher than that of homogeneous polyacrylonitrile membrane. As the polyacrylonitrile content decreases, the ethanol flux increases and the separation factor drops accordingly. In the polyacrylonitrile contents ranging between 70 and $95 \mathrm{wt} \%$, water flux remains over $0.1 \mathrm{~kg} \mathrm{~m}^{-2} \mathrm{~h}^{-1}$ and ethanol flux stays still low. Cellulose acetate was expected to serve as a component to increase the solubility selectivity of water in the blend membrane by providing more sorption sites of water. The results of the present study indicated that blending with $\mathrm{CA}$ appeared to raise the solubility of water and the diffusion coefficients of both water and even more ethanol across the blend membrane, and thus decrease the separation factor. Besides the blending with CA, solvent evaporation rate might be one of 
Table II. Effect of solvent evaporation temperature during PAN $/ C A=90 / 10$ blend membrane manufacturing on pervaporation performance

\begin{tabular}{|c|c|c|c|c|c|c|c|}
\hline $\begin{array}{c}\text { Solvent } \\
\text { evaporation } \\
\text { pressure }\end{array}$ & $\begin{array}{c}\text { Solvent } \\
\text { evaporation } \\
\text { temperature }\end{array}$ & $\begin{array}{l}\text { Membrane } \\
\text { thickness, } L\end{array}$ & $\begin{array}{c}\text { Total } \\
\text { flux, } Q\end{array}$ & $Q \times L$ & $Q_{\mathrm{w}} \times L$ & $Q_{\mathrm{e}} \times L$ & $\alpha$ \\
\hline $\mathrm{mmHg}$ & ${ }^{\circ} \mathrm{C}$ & $\mu \mathrm{m}$ & $\mathrm{g} \mathrm{m}^{-2} \mathrm{~h}^{-1}$ & $\mathrm{~g} \cdot \mu \mathrm{m} \cdot \mathrm{m}^{-2} \mathrm{~h}^{-1}$ & $\mathrm{~g} \cdot \mu \mathrm{m} \cdot \mathrm{m}^{-2} \mathrm{~h}^{-1}$ & $\mathrm{~g} \cdot \mu \mathrm{m} \cdot \mathrm{m}^{-2} \mathrm{~h}^{-}$ & -1 \\
\hline 160 & 40 & 23 & 31 & 713 & 710 & 3 & 2548 \\
\hline 160 & 60 & 15 & 202 & 3030 & 3001 & 29 & 913 \\
\hline 160 & 60 & 36 & 79 & 2844 & 2843 & 1 & 19700 \\
\hline 160 & 80 & 25 & 100 & 2500 & 2483 & 17 & 1233 \\
\hline 460 & 40 & 14 & 92 & 1288 & 859 & 429 & 20 \\
\hline 460 & 40 & 35 & 40 & 1400 & 1369 & 4 & 3200 \\
\hline 460 & 60 & 25 & 79 & 1975 & 1781 & 194 & 78 \\
\hline 460 & 80 & 15 & 117 & 1755 & 807 & 945 & 8 \\
\hline 660 & 40 & 27 & 152 & 4104 & 878 & 3226 & 2 \\
\hline 760 & 60 & 13 & 113 & 1470 & 1443 & 27 & 606 \\
\hline 760 & 60 & 33 & 49 & 1617 & 1583 & 34 & 410 \\
\hline 760 & 80 & 25 & 157 & 3925 & 3914 & 11 & 2923 \\
\hline
\end{tabular}

the factors influencing the pervaporation performance.

From this study, we conducted a BoxBehnken designed experiment with four factors taken at three levels. Four factors considered are blend ratio of PAN/CA, membrane thickness, solvent evaporation temperature and solvent evaporation pressure. The responses we looked into were water flux and concentration of water in the permeate.

For PAN $/ \mathrm{CA}=90 / 10$ blend membranes, the effect of membrane thickness on pervaporation performance is illustrated in Figure 5. As membrane thickness decreases, flux increases and more so for ethanol flux, resulting in a rapid drop in separation factor. This behavior is also observed by Smolders et al. ${ }^{10}$ and is regarded as a deviation from the solutiondiffusion model.

Solvent evaporation rate is increased with solvent evaporation temperature and with a decrease in the solvent evaporation pressure (see Table II). Changing the solvent evaporation temperature and pressure results in fluxes and selectivity that are significantly influenced as expected. Scanning electron microscope pictures reveal that the membranes with

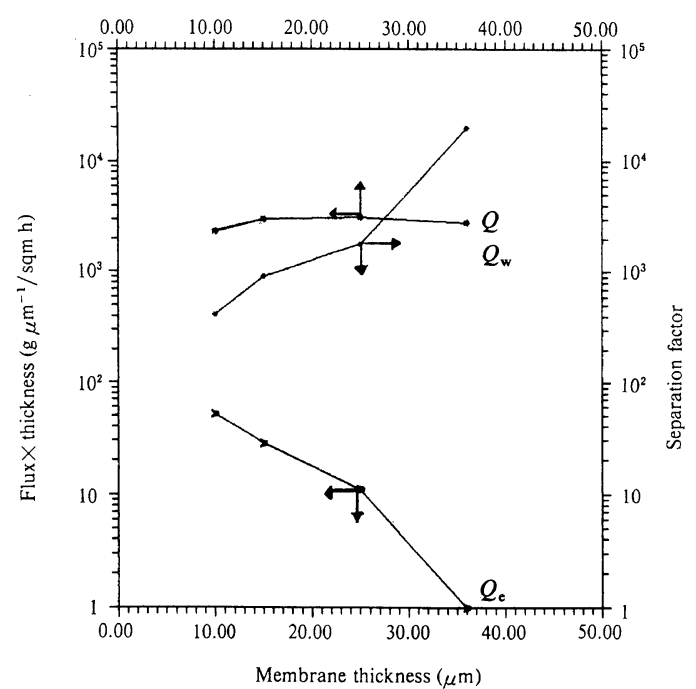

Figure 5. Effect of thickness of $P A N / C A=90 / 10$ membrane on pervaporation performance.

high permeation flux and separation factor are asymmetric in structure with dense layer on top of porous sublayer, while membranes with low flux but high separation factor are homogeneous and dense over the whole cross-section of the membrane. Thus, we can draw a tentative conclusion that the membrane morphology must play an important role in 
Table III. Pervaporation performance of polyacrylonitrile membranes

\begin{tabular}{|c|c|c|c|c|c|c|c|}
\hline $\begin{array}{c}\text { Solvent } \\
\text { evaporation } \\
\text { pressure }\end{array}$ & $\begin{array}{c}\text { Solvent } \\
\text { evaporation } \\
\text { temperature }\end{array}$ & $\begin{array}{l}\text { Membrane } \\
\text { thickness, } L\end{array}$ & $\begin{array}{c}\text { Total } \\
\text { flux, } Q\end{array}$ & $Q \times L$ & $Q_{\mathrm{w}} \times L$ & $Q_{\mathrm{e}} \times L$ & $\alpha$ \\
\hline$m m H g$ & ${ }^{\circ} \mathrm{C}$ & $\mu \mathrm{m}$ & $\mathrm{g} \mathrm{m}^{-2} \mathrm{~h}^{-1}$ & $\mathrm{~g} \cdot \mu \mathrm{m} \cdot \mathrm{m}^{-2} \mathrm{~h}^{-1}$ & $\mathrm{~g} \cdot \mu \mathrm{m} \cdot \mathrm{m}^{-2} \mathrm{~h}^{-1}$ & $\mathrm{~g} \cdot \mu \mathrm{m} \cdot \mathrm{m}^{-2} \mathrm{~h}^{-}$ & \\
\hline 160 & 60 & 22 & 56 & 1232 & 1228 & 4 & 2136 \\
\hline 460 & 60 & 13 & 111 & 1443 & 1401 & 42 & 199 \\
\hline 460 & 60 & 33 & 43 & 1419 & 1417 & 2 & 9408 \\
\hline 760 & 60 & 22 & 123 & 2706 & 2703 & 3 & 3696 \\
\hline
\end{tabular}

Table IV. Pervaporation performance of PAN $/ \mathrm{CA}=80 / 20$ blend membranes

\begin{tabular}{|c|c|c|c|c|c|c|c|}
\hline $\begin{array}{c}\text { Solvent } \\
\text { evaporation } \\
\text { pressure }\end{array}$ & $\begin{array}{c}\text { Solvent } \\
\text { evaporation } \\
\text { temperature }\end{array}$ & $\begin{array}{l}\text { Membrane } \\
\text { thickness, } L\end{array}$ & $\begin{array}{c}\text { Total } \\
\text { flux, } Q\end{array}$ & $Q \times L$ & $Q_{\mathrm{w}} \times L$ & $Q_{\mathrm{e}} \times L$ & $\alpha$ \\
\hline $\mathrm{mmHg}$ & ${ }^{\circ} \mathrm{C}$ & $\mu \mathrm{m}$ & $\mathrm{g} \mathrm{m}^{-2} \mathrm{~h}^{-1}$ & $\mathrm{~g} \cdot \mu \mathrm{m} \cdot \mathrm{m}^{-2} \mathrm{~h}^{-1}$ & $\mathrm{~g} \cdot \mu \mathrm{m} \cdot \mathrm{m}^{-2} \mathrm{~h}^{-1}$ & $\mathrm{~g} \cdot \mu \mathrm{m} \cdot \mathrm{m}^{-2} \mathrm{~h}$ & $1^{-1}$ \\
\hline 160 & 60 & 27 & 77 & 2079 & 2077 & 2 & 13653 \\
\hline 460 & 40 & 22 & 51 & 1122 & 1001 & 121 & 68 \\
\hline 460 & 60 & 13 & 357 & 4641 & 1254 & 3387 & 3 \\
\hline 460 & 60 & 37 & 60 & 2220 & 2218 & 2 & 13040 \\
\hline 460 & 80 & 23 & 72 & 1656 & 1652 & 4 & 4963 \\
\hline 760 & 60 & 27 & 112 & 3024 & 3022 & 2 & 12922 \\
\hline
\end{tabular}

permeation behavior. For homogeneous polyacrylonitrile membranes as shown in Table III, solution and water flux increase and ethanol permeation rate remains relatively constant as solvent evaporation pressure increases when $90 \mathrm{wt} \%$ ethanol is used as a feed solution. This can be explained from the fact that as the evaporation rate is increased, the membrane becomes dense and thus the separation factor could be increased. In a PAN/CA $(80: 20)$ blend membrane, permeation flux would increase with the solvent evaporation pressure. Here again, solvent evaporation rate plays an important role in the permeation rate. Note the very high separation factor when membrane thickness exceeds $20 \mu \mathrm{m}$ (Table IV).

\section{Poly (acrylonitrile-co-acrylic acid) Membrane}

Selective separations of solute require strong adsorptions through membranes caused by a strong interaction such as hydrogen bonding.
It is expected that the carboxyl groups might have a strong interaction with water through hydrogen bonding and a membrane containing a carboxyl group might selectively permeate water due to increased solubility selectivity. In this context, a copolymer from acrylonitrile and acrylic acid was synthesized. Poly(acrylonitrile-co-acrylic acid) used here was manufactured by an usual radical copolymerization of acrylonitrile and acrylic acid which were initiated by ammonium persulfate in $60 \%$ aqueous zine chloride solution at $60^{\circ} \mathrm{C}$. The membrane was obtained by casting from the DMF solution of the copolymer. The membrane thickness was $c a .20 \mu \mathrm{m}$.

Figure 6 shows an effect of acrylic acid content in copolymer on flux and separation factor. Compared with homogeneous polyacrylonitrile membrane, acrylic acid containing membrane shows a slight decrease in total flux and water flux and a marked drop in ethanol 


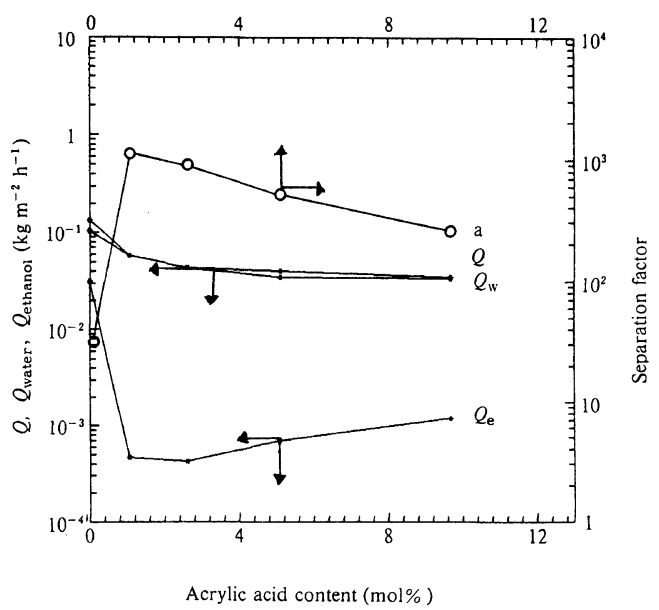

Figure 6. Effect of acrylic acid content in poly(acrylonitrile-co-acrylic acid) membrane on membrane performance. Feed solution $=90 \mathrm{wt} \%$ ethanol; feed temperature $=25^{\circ} \mathrm{C}$; membrane thickness $=20 \mu \mathrm{m}$.

flux. Accordingly, acrylic acid containing polymers have better pervaporation performance than that of pure polyacrylonitrile membrane. As acrylic acid contents increase further, solution flux and water flux decrease to some extents while ethanol flux shows a reverse trend. The separation factor, therefore, drops when the acrylic acid content is greater than $2.6 \%$. This result is compared with Yoshikawa et al.'s data ${ }^{7}$ where they reported separation factor of similar polymer reaches 880 and flux was only about $7 \mathrm{~g} \mathrm{~m}^{-2} \mathrm{~h}^{-1}$ when the weight fraction of water in feed was around 0.185 and feed temperature was at $15^{\circ} \mathrm{C}$. From the present study we obtained separation factor of above 1000 where weight fraction of water in the feed is around 0.1 at $25^{\circ} \mathrm{C}$. Note that the flux from this study is about ten times greater than that reported in the literature. ${ }^{7}$

\section{CONCLUSIONS}

We have investigated various ways to improve the membrane morphology and the membrane performance of the polyacrylonitrile membranes. The key factors affecting the membrane mophology include the membrane thickness and membrane casting variables such as the concentration of casting solution, solvent evaporation temperature, solvent evaporation pressure and the presence of nonsolvents in the casting solution. Throughout this study we have established a preparative method of modified polyacrylonitrile membranes for ethanol dehydration with an improved permeation characteristics and with a minimal sacrifice of separation factor. Blending the polyacrylonitrile with cellulose acetate enhances permeation flux about ten times that of homogeneous polyacrylonitrile membranes, while separation factor remains more than 1000. For these membranes we were able to effectively predict the pervaporation performance based on the knowledge of solvent evaporation rate during the membrane preparation process. Copolymerization with acrylic acid increases hydrophilicity in the base polymer and thus improves water sorption and the separation characteristics of water from aqueous ethanol solution.

Acknowledgments. Authors greatly appreciate the financial support of the part of this work from Kolon Engineering Co. PAN samples from Hanil Synthetic Fibers Co. are also appreciated.

\section{REFERENCES}

1. Y. M. Lee, K. Bourgeois, and G. Belfort, $J$. Membrane Sci., 44, 161 (1989).

2. I. Cabasso and Z.-Z. Liu, J. Membrane Sci., 24, 101 (1985).

3. A. Wenzlaff, K. W. Boddeker, and K. Hattenbach, J. Membrane Sci., 22, 333 (1985).

4. T. Hirotsu, K. Ichimura, K. Mizoguchi, and E. Nakamura, J. Appl. Polym. Sci., 36, 1717 (1988).

5. C. E. Reineke, J. A. Jagodzinske, and K. R. Denslow, J. Membrane Sci., 32, 207 (1987).

6. Q. T. Nguyen, L. Le Blanc, and J. Neel, J. Membrane Sci., 22, 245 (1985).

7. M. Yoshikawa, T. Yukoshi, K. Sanui, and N. Ogata, J. Poly. Sci., Poly. Lett. Ed., 22, 473 (1984).

8. M. Yoshikawa, H. Yokoi, K. Sanui, and N. Ogata J. Polym. Sci., Polym. Chem. Ed., 22, 2159 (1984).

9. M. Yoshikawa, T. Yukoshi, K. Sanei, and N. Ogata, 
Polym. J., 18, 447 (1986).

10. J. W. F. Spitzen, G. H. Koops, M. H. V. Mulder, and C. A. Smolders, Proceeding of Third International Conference on Pervaporation Processes in the Chemical Industry, held in Nancy, France, Sept. 19-22, 1988, p 252.

11. SAS Institute, Cary, NC, U.S.A. (1985).

12. R. E. Kesting, J. Polym. Sci., C: Polym. Lett., 27, 1870 (1989).

13. R. T. Chern, W. T. Koros, H. P. Hopfenberg, and V. T. Stannett, in "Materials Science of Synthetic
Membranes," K. Lloyd, Ed., ACS Symp. Series 269, 1985.

14. Y. M. Lee and Y. D. Moon, unpublished result.

15. M. H. V. Mulder, J. Oude Hendrikman, H. Hegeman and C. A. Smolders, J. Membrane Sci., 16, 269 (1983).

16. H. J. C. te Hennepe, K. Bargeman, M. H. B, Mulder, and C. A. Smolders, Prodeedings of Second International Conference on pervaporation Processes in the Chemical Industry, held in San Antonio, Texas, U.S.A., March 8-11, 1987, p 71. 